\title{
Investigation of the Potential Use of Tidal Current Turbines in the Ocean City, Maryland Inlet for Renewable Energy Generation
}

\author{
Mark W. Muller*, Zachary Rue, Krista Hiebler \\ Department of Physics, Salisbury University, Salisbury, MD, USA \\ Email: "mwmuller@salisbury.edu
}

Received 3 March 2016; accepted 17 April 2016; published 20 April 2016

Copyright $@ 2016$ by authors and Scientific Research Publishing Inc.

This work is licensed under the Creative Commons Attribution International License (CC BY). http://creativecommons.org/licenses/by/4.0/

\section{(c) (i) Open Access}

\begin{abstract}
There is enormous potential and interest in renewable energy generation from marine tidal currents. Tidal currents have been recognized as a valuable resource for the sustainable generation of electrical power. Tidal currents are particularly attractive for power generation and advantageous when compared to other renewable energies due to their high predictability and fluid properties. The inlet between Ocean City, Maryland and Assateague Island has highly predictable tides and may have potential as a resource for renewable energy generation. In this paper, measurements of the tidal current velocity are made at various locations within the inlet. Measurements are made near the surface due to the energy flux of tidal channels being higher near the surface. The data show that the inlet is a potential candidate for deployment of vertical axis tidal turbines for small-scale renewable energy generation.
\end{abstract}

\section{Keywords}

Tidal Currents, Tidal Energy, Tidal Turbines, Renewable Energy

\section{Introduction}

According to [1], the ocean may have enough energy in the form of tides, waves, currents, and heat to meet the total worldwide energy demand many times over. Interest in generating power from the ocean tides and currents without the need to capture water in a basin or the need to construct a barrage has existed since at least the 1970s

${ }^{*}$ Corresponding author.

How to cite this paper: Muller, M.W., Rue, Z. and Hiebler, K. (2016) Investigation of the Potential Use of Tidal Current Turbines in the Ocean City, Maryland Inlet for Renewable Energy Generation. Smart Grid and Renewable Energy, 7, $142-146$. 
[2] [3]. More recently there has been a considerable interest in the utilization of tidal currents in coastal areas to generate power [4]-[6]. Tidal power is a highly predictable renewable energy source, which gives it an advantage over other forms of renewable energy such as wind energy, solar energy, and wave energy.

Tidal energy has both kinetic energy and potential energy components. Tidal power generation technologies can be categorized into two distinct types: tidal current turbines and tidal barrages, which use the kinetic and potential energy of the tides respectively [7]. Tidal barrages are advantageous in areas which experience large variations in the tidal ranges (for more information on tidal barrages see [8]). For example, the tides in the Bay of Fundy, Canada have an amplitude variation between 52.5 and 55.8 feet near shore, which are the greatest in the world [9] thus making it an excellent candidate for tidal barrages.

In areas where tide level variations are not as extreme, tidal current turbines which extract the kinetic energy from moving water for electricity generation offer an attractive alternative. Tidal current technology is similar to wind energy technology despite several differences in operating conditions [10]. Some tidal turbines resemble underwater wind turbines and require tidal current speeds of 6.5 - $9.8 \mathrm{fps}$ for large-scale power generation; at speeds below $6.5 \mathrm{fps}$, energy harnessing is considered uneconomical while speeds above $9.8 \mathrm{fps}$ can damage the turbines [11]. However small-scale power generation is possible when the tidal current speed is only 3.3 fps using a Darrieus turbine, which achieves its highest efficiency at a tip speed ratio equal to 2.1, over 3.6 fps of tidal speed flow [12].

In this paper, a preliminary investigation of the tidal current in the inlet between Ocean City, Maryland and Assateague Island, Maryland (see Figure 1) is conducted to determine its potential as a renewable energy source. (For a cartographic map of the Ocean City, Maryland inlet, see Marine Chart: US12211_P553.) The inlet ebb and flow tidal currents are predictable and consistent; however the current velocity profile of the inlet is not well documented. Tidal current speed is measured at predetermined locations within the inlet to determine whether large-scale or small-scale power generation may be possible and which location(s) would be optimal for deploying tidal power generation technology.

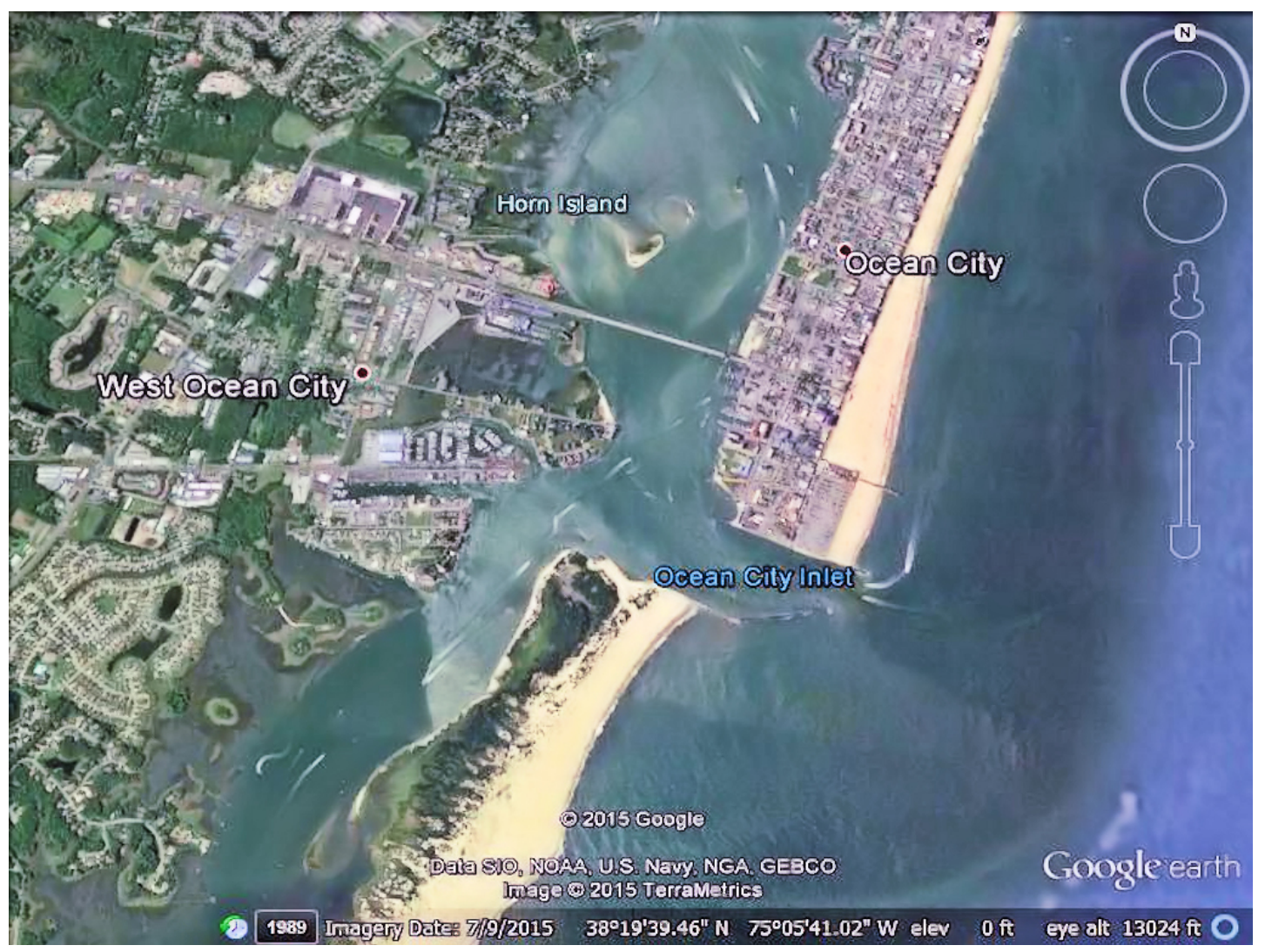

Figure 1. Aerial view of the Ocean City, MD Inlet (Source: “Ocean City Inlet”, 38¹9'39.46"N and 7505'41.02"W, Google Earth, July 9, 2015, December 5, 2015). 


\section{Methods and Materials}

Seven data collection trips of the inlet tidal current were conducted on a 20' motor vessel between September and November 2015. The motor vessel is equipped with a Garmin GPSmap 182C which provides the longitude and latitude coordinates of the vessel's position. The motor vessel is also equipped with a Garmin Fishfinder $34^{\circ} \mathrm{C}$ with a 50/200 kHz dual frequency transducer which provides depth measurements as well as water temperature. Data collection trips occurred between 19:30 and 20:30 GMT on each of the respective days. Tide times and levels provided by the National Oceanic and Atmospheric Administration (NOAA)

(https://tidesandcurrents.noaa.gov/) were recorded for each data collection trip.

Tidal current speeds were measured using a Global Water digital water velocity flow probe meter. The water velocity probe consists of a protected water turbo prop positive displacement sensor coupled with an expandable probe handle up to 15 ' and ending in a digital readout display. The water velocity probe has a range of $0.3-19.9$ fps with an accuracy of $0.1 \mathrm{fps}$. The tidal flow velocity was measured at depths of 4.33 feet, 5.50 feet, and 6.25 feet below the surface at each location for a duration of $60 \mathrm{~s}$. Data was collected near the surface as opposed to near the bottom because the energy flux in a tidal channel is higher near the surface [13]. Six data collection sites were chosen prior to the start of the data collection trips and are provided with their respective longitude and latitude coordinates in Figure 2. The average and maximum flow velocities were recorded at each depth at each of the respective collection sites.

\section{Results}

The most consistent and highest magnitude flow speeds occurred at 6.25 feet below the surface for all sites. Table 1 shows the average flow speed measured at a depth of 6.25 at each specific data collection site for each data collection trip. Seven total data collection trips were conducted. Data from one of the trips is omitted from Table 1 due to malfunctioning equipment during that specific trip. During trip \#4, accurate data could not be captured at site 2 due to heavy and dangerous wave activity. Table 1 also shows the average depth at each collection site provided by the Garmin Fishfinder $34^{\circ} \mathrm{C}$, the low tide and high tide times provided by NOAA, and the mean lower low water (MLLW) and the mean higher high water (MHHW) levels provided by NOAA.

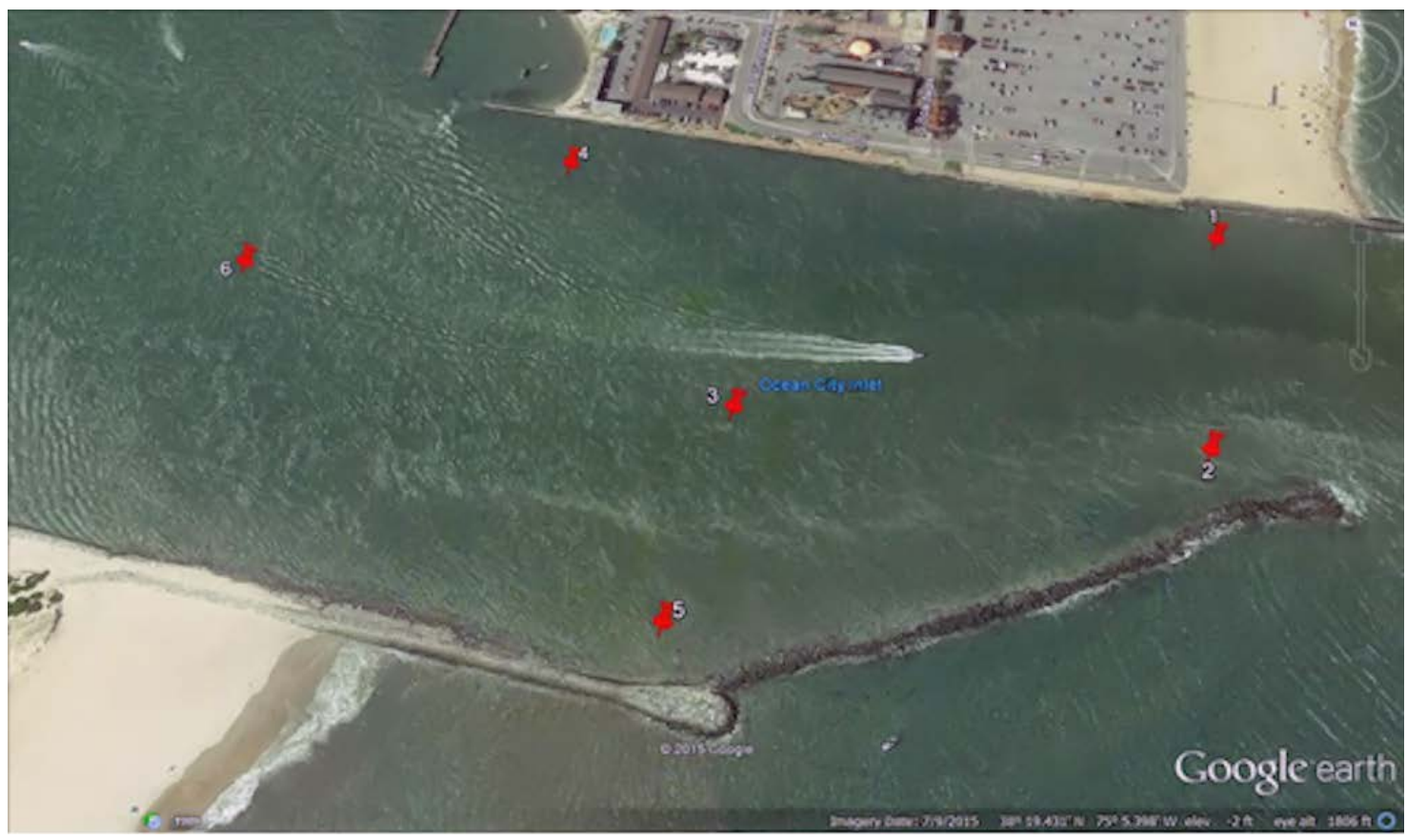

Figure 2. Zoomed in aerial view of the Ocean City Inlet with data collection sites indicated and their respective coordinates indicated (Source: “Ocean City Inlet”, 38 $19.431^{\prime} \mathrm{N}$ and $75^{\circ} 5.398^{\prime} \mathrm{W}$, Google Earth, July 9, 2015, December 8, 2015). (1) N38 $19.46^{\prime}, \mathrm{W} 75^{\circ} 05.19^{\prime}$; (2) N38 $19.39^{\prime}, \mathrm{W} 75^{\circ} 05.23^{\prime}$; (3) N38 $19.43^{\prime}, \mathrm{W}^{\circ} 05^{\circ} 05.39^{\prime}$; (4) N38 $19.53^{\prime}$, W $75^{\circ} 05.43^{\prime} ;$ (5) N38 $19.37^{\prime}, \mathrm{W} 75^{\circ} 05.43^{\prime} ;$ (6) N38 $19.51^{\prime}, \mathrm{W} 75^{\circ} 05.56^{\prime}$. 
Table 1. Table of the average depth at each collection site, the average flow speed for each trip at a depth of 2.2' at each site, the average flow speed for all trips, low and high tide times on each respective day, and the mean lower low water and the mean higher high water levels on each respective day.

\begin{tabular}{cccccccccccc}
\hline & Site 1 & Site 2 & Site 3 & Site 4 & Site 5 & Site 6 $\begin{array}{c}\text { Low Tide } \\
\text { (GMT) }\end{array}$ & $\begin{array}{c}\text { High Tide } \\
\text { (GMT) }\end{array}$ & $\begin{array}{c}\text { MLLW } \\
\text { (ft) }\end{array}$ & $\begin{array}{c}\text { MHHW } \\
\text { (ft) }\end{array}$ \\
\hline Avg. Depth of Site (ft) & 25 & 27.5 & 16.5 & 17 & 12 & 18 & & & & & \\
Trip 1 Avg. Flow Speed (fps) & 5.0 & 5.2 & 2.2 & 2.4 & 3.1 & 3.2 & $20: 36$ & $14: 17$ & -2.001 & 0.463 \\
Trip 2 Avg. Flow Speed (fps) & 5.3 & 2.4 & 4.1 & 3.2 & 3.8 & 3.8 & $14: 29$ & $21: 01$ & 0.928 & 3.392 \\
Trip 3 Avg. Flow Speed (fps) & 2.5 & 0.7 & 2.9 & 2.9 & 0.1 & 2.6 & $12: 30$ & $18: 53$ & -1.040 & 1.424 \\
Trip 4 Avg. Flow Speed (fps) & 2.7 & N/A & 3.3 & 3.3 & 3.0 & 2.2 & $19: 29$ & $13: 06$ & -1.848 & 1.030 \\
Trip 5 Avg. Flow Speed (fps) & 3.0 & 2.5 & 3.0 & 3.0 & 0.7 & 2.0 & $11: 57$ & $18: 16$ & -0.197 & 2.267 \\
Trip 6 Avg. Flow Speed (fps) & 1.8 & 1.8 & 0.2 & 0.2 & 0.2 & 1.2 & $17: 54$ & $23: 51$ & -0.633 & 1.831 \\
Overall Avg. Flow Speed (fps) & 3.4 & 2.5 & 2.6 & 2.5 & 1.8 & 2.5 & & & & \\
\hline
\end{tabular}

\section{Discussion}

The data suggest that there may be sufficient kinetic energy in the tidal flow of the inlet for small-scale renewable energy generation. The data suggest that the inlet is not a strong candidate for large-scale renewable energy generation due to the relatively small variation in tidal levels, relatively low water flow velocities, and insufficient space for a tidal barrage. However there is sufficient space and tidal flow kinetic energy for use of a smallscale energy generating device such as a vertical axis tidal turbine (VATT) [14].

The data suggest that out of the six tested sites, site 1 has the best potential for deployment of a VATT. Site 1 has the highest overall water flow speed average and the most consistent speed values when compared to the other data collection sites. Another advantage of site 1 is it is located on the Ocean City side of the inlet and it would not require cables to be run across the inlet channel to transfer the energy from a VATT to the municipality. From visual observations made over the seven trips, site 1 does not have any wave breaking action on the surface and the flow is consistently steady.

The data show that sites 2, 3, 4, and 6 all have similar overall average flow speeds. From observations, site 2 is the most turbulent and has the most surface wave breaking action. Site 2 has more sporadic flow velocity numbers and a lower overall average flow velocity than site 1 . Site 2 generally has high surface flow velocity for a flowing tide and has the highest surface flow velocity out of all sites due to the nozzle effect of the inlet. However due to the wave action and turbulence, site 2 is not a strong candidate for deployment of a VATT on a floating structure mount or a near-surface structure mount. From visual observations, sites 3 and 6 have steady flow; however the overall speeds are lower than site 1 . However, sites 3 and 6 are in the middle of the traffic channel and thus are not strong candidates for deployment of a near-surface VATT. A VATT on a bottom structure mount may be an option; however it would compromise the navigational depth and the energy flux of the tidal flow may be significantly lower. Site 4 is a strong candidate for VATT deployment due to its proximity to the municipality and observations of steady and relatively high surface flow velocities. From observations, the flow at site 4 is steady with negligible wave action; however the data suggest that the average measured flow speed is less than site 1 . Site 5 has the lowest overall average flow speed. From observations, site 5 has inconsistent flow and sometimes an induced large eddy due to the geometry of the inlet. Considering these factors and site 5's location in the inlet, site 5 would not be a candidate for deployment of a VATT.

Site 1 is the best candidate for renewable energy generation out of the six sites tested. There is enough depth and flow speed at site 1 to deploy and test a cross flow VATT such as a Darrieus turbine [12] or a helical turbine [9]. Consider the expression for turbine power of a floating VATT in a free, unconstrained tidal current:

$$
P_{t}=0.5 \eta \rho A V^{3}
$$

where $P_{t}$ is the turbine power in kilowatts, $\eta$ is the turbine efficiency, $A$ is the total effective frontal area of the turbines $\mathrm{m}^{2}$ (cross-section of the flow where the turbine are installed), $\rho$ is the mass water density, and $V$ is the tidal current velocity in $\mathrm{m} / \mathrm{s}$. If we take $\eta=0.35$ (from the tests of a helical turbine, [9]), a standard density of 
sea water $\rho=1029 \mathrm{~kg} / \mathrm{m}^{3}, A=1.32 \mathrm{~m}^{2}$ [15], and the average flow velocity from site $1 \mathrm{~V}=1.04 \mathrm{~m} / \mathrm{s}$ (3.4 fps), then $P_{t}=267 \mathrm{~W}$. The helical or Darrieus VATT can be mounted either on a floating structure which is moored to the seafloor using chains or wires as shown in [10] or using a near-surface mounting structure like the one shown in [13]. Although a cost analysis should be performed to estimate the cost of energy per unit and a full power performance study of different VATT designs will have to be investigated, the inlet is a strong candidate for small-scale renewable energy production based on this investigative study.

\section{References}

[1] Takahashi, P. and Trenka, A. (1996) Ocean Thermal Energy Conversion. Wiley, New York.

[2] Heronomus, W.E., Margarella, P.A., McPherson, R.A. and Ewing, D.L. (1974) On the Extraction of Kinetic Energy from Oceanic and Tidal River Currents. In: Stewart, H.B., Ed., MacArthur Workshop on the Feasibility of Extracting Useable Energy from the Florida Current, Palm Beach Shores, Florida.

[3] Lissaman, P.B.S. and Radkey, R.L.L. (1979) Coriolis Program: A Review of the Status of the Ocean Turbine Energy System. Oceans'79, London, 17-19 September 1979, 559-565. http://dx.doi.org/10.1109/oceans.1979.1151217

[4] Cave, P.R. and Evans, E.M. (1984) Tidal Stream Energy Systems for Isolated Communities. In: West, M.J., et al., Eds., Alternative Energy Systems-Electrical Integration and Utilization, Pergamon Press, Oxford. http://dx.doi.org/10.1016/B978-0-08-031639-0.50007-6

[5] Bryden, I.G., Bullen, C., Baine, M. and Paish, O. (1995) Generating Electricity from Tidal Currents in Orkeny and Shetland. Underwater Technology, 21, 21-29. http://dx.doi.org/10.3723/175605495783326649

[6] Sodin, H. (2001) Scotland's Renewable Resource 2001. Scottish Executive Publications, Edinburgh.

[7] Lemonis, G. and Cutler, J.C. (2004) Wave and Tidal Energy Conversion. In: Encyclopedia of Energy, Elsevier, New York, 385-396. http://dx.doi.org/10.1016/B0-12-176480-X/00344-2

[8] Boyle, G. (2004) Renewable Energy Power for a Sustainable Future. 2nd Edition, Oxford University Press, Oxford.

[9] Gorlov, A.M. (2001) Tidal Energy. Academic Press, Boston, 2955-2960.

[10] O’Rourke, F., Boyle, F. and Reynolds, A. (2010) Tidal Energy Update 2009. Applied Energy, 87, 398-409. http://dx.doi.org/10.1016/j.apenergy.2009.08.014

[11] Pelc, R. and Fujita, R.M. (2002) Renewable Energy from the Ocean. Marine Policy, 26, 471-479. http://dx.doi.org/10.1016/S0308-597X(02)00045-3

[12] Kiho, S., Shiono, M. and Suzuki, K. (1996) The Power Generation from Tidal Currents by Darrius Turbine. Journal of Renewable and Sustainable Energy, 9, 1242-1245.

[13] Khan, M.J., Bhuyan, G., Iqbal, M.T. and Quaicoe, J.E. (2009) Hydrokinetic Energy Conversion Systems and Assessment of Horizontal and Vertical Axis Turbines for River and Tidal Applications: A Technology Status Review. Applied Energy, 86, 1823-1835. http://dx.doi.org/10.1016/j.apenergy.2009.02.017

[14] Khalid, S.S., Liang, Z. and Shah, N. (2012) Harnessing Tidal Energy Using Vertical Axis Tidal Turbine. Research Journal of Applied Sciences, Engineering and Technology, 5, 239-252.

[15] Bachant, P. and Wosnik, M. (2011) Experimental Investigation of Helical Cross-Flow Axis Hydrokinetic Turbines, Including Effects of Waves and Turbulence. Proceedings of ASME-JSME-KSME Joint Fluids Engineering Conference, Hamamatsu, 24-29 July 2011, 1895-1906. 